\title{
Fas-associated factor 1 inhibits tumor growth by suppressing Helicobacter pylori-induced activation of NF-KB signaling in human gastric carcinoma
}

\author{
Ai-qun Liu ${ }^{1}$, Zhongqiu Xie ${ }^{2}$, Xiao-ni Chen ${ }^{1}$, Jie Feng ${ }^{1}$, Jia-wei Chen ${ }^{1}$, Fu-jun Qin ${ }^{2}$, \\ Lian-ying $\mathbf{G e}^{1}$ \\ ${ }^{1}$ Department of Endoscopy, The Affiliated Tumor Hospital of Guangxi Medical University, Nanning 530021, Guangxi, P.R. \\ China \\ ${ }^{2}$ Department of Pathology, School of Medicine, University of Virginia, Charlottesville, VA 22908, USA \\ Correspondence to: Ai-qun Liv, email: livaiqun_2004@hotmail.com \\ Lian-ying Ge, email: gelianying2008@163.com
}

Keywords: gastric cancer, Fas-associated factor 1, NF-KB, Helicobacter pylori

Abbreviations: FAFl, Fas-associated factor 1; H. pylori, Helicobacter pylori; IL-8, interleukin-8; NF-KB, nuclear factor-KB; TNF-a, tumor necrosis factor- $\alpha$

Published: December 20, 2016

\section{ABSTRACT}

Loss of Fas-associated factor 1 (FAF1) may act as a pro-survival signal in diseased cells, but whether this is true in gastric carcinoma remains unclear. Here we report that FAF1 was expressed at low levels in gastric carcinoma tissues and cell lines, and its expression correlated with larger tumors, higher histology grade, higher TNM stage, tumor infiltration, and lymph node metastasis. Univariate analysis and survival curve analysis identified Iow FAF1 expression as a predictor of poor prognosis. FAF1 overexpression in HGC-27 gastric cancer cells induced cell apoptosis and inhibited cell proliferation and growth. It also reduced colony formation in vitro and tumor growth in mice. We found that Helicobacter pylori, a risk factor for gastric cancer, down-regulated FAF1 expression via NF-KB signaling. Knock-down of IKK $\beta$ or p65 expression in gastric cancer cells reversed $\boldsymbol{H}$. pylori-induced down-regulation of FAF1 expression and partially blocked $H$. pylori-induced secretion of inflammatory cytokines TNF-a and IL-8. Our results suggest that loss of FAF1 contributes to human gastric carcinogenesis by allowing $H$. pylori to activate NF-KB signaling.

\section{INTRODUCTION}

Gastric cancer is the fourth most common human cancer in the world, with approximately 934,000 new cases and 73,800 deaths occuring every year. More than $70 \%$ of gastric cancer cases occur in developing countries, with nearly half of all cases occurring in China [1]. Despite rapid advancements in surgery, chemotherapy, and radiation therapies for gastric cancer, 5-year overall survival remains around $29 \%$ because of tumor recurrence and distant metastases [2]. Therefore, there is an urgent need to reveal the molecular mechanisms underlying gastric carcinoma in order to develop novel therapeutic strategies.

Fas-associated factor 1 (FAF1), a 74-kDa proapoptotic protein also known as Fas antigen, is involved in diverse biological processes [3], and its loss has been reported in uterine cervical carcinoma [4], mantle cell lymphoma [5] and malignant mesothelioma [6]. In previous work, we showed that FAF1 mRNA levels are lower in gastric cancer tissue, especially in poorly differentiated tumors, than in healthy gastric tissue [7]. These results suggested that FAF1 plays a role in the progression of gastric carcinogenesis.

Further evidence for this idea comes from the association between FAF1 expression and infection with Helicobacter pylori, a Group I carcinogen in gastric carcinogenesis [8]. H. pylori infection is strongly linked to the development of gastritis, peptic ulcers, gastric atrophy and gastric cancer [9]. Our laboratory has shown that among gastric cancer patients, FAF1 mRNA levels are lower in tissues positive for $H$. pylori than in tissues negative for $H$. pylori [7]. H. pylori may increase risk of gastric cancer in part by activating $\mathrm{NF}-\kappa \mathrm{B}$ signaling $[10$, 11], leading to secretion of pro-inflammatory cytokines 
such as tumor necrosis factor- $\alpha(\mathrm{TNF}-\alpha)$, interleukin-1 (IL$1 \beta$ ), interleukin-6 (IL-6) and interleukin-8 (IL-8). Therefore we wondered whether FAF1 may be affected by $\mathrm{NF}-\kappa \mathrm{B}$ signaling.

To gain deeper insights into the potential role of FAF1 in gastric cancer, we determined levels of FAF1 expression in gastric carcinoma tissues and cell lines, and we examined the effects of FAF1 overexpression on tumor cell proliferation in vitro and tumor growth in vivo. We retrospectively analyzed clinical data in order to identify possible relationships of FAF1 expression with patient or disease characteristics or with prognosis. Finally, we examined whether FAF1 may influence gastric carcinogenesis by inhibiting $H$. pyloriinduced $\mathrm{NF}-\kappa \mathrm{B}$ activation.

\section{RESULTS}

\section{Low FAF1 expression characterizes human gastric carcinoma and predicts poor prognosis}

FAF1 protein expression was measured using immunohistochemistry in samples of gastric cancer tissue, adjacent tissue and normal gastric tissue from 145 patients with gastric cancer. FAF1 was weakly expressed in gastric cancer tissue, but strongly expressed in adjacent tissue or normal gastric tissue (Figure $1 \mathrm{~A}$ a-d). Comparison of FAF1 expression with clinicopathological characteristics (Table 1) identified negative associations of FAF1 expression with tumor size $(\mathrm{P}=0.024)$, histology grade $(\mathrm{P}<0.01)$, tumor infiltration $(\mathrm{P}<0.01)$, lymph node metastasis $(\mathrm{P}<0.01)$, and TNM stage $(\mathrm{P}<0.01)$. Univariate analysis identified the following predictors of survival: FAF1 expression, tumor diameter, tumor location, tumor infiltration, histology grade, lymph node metastasis, distant metastasis and TNM stage (Table 2). Stratification of patients by FAF1 expression and comparison of their survival curves showed lower survival rate among those with low FAF1 expression (Figure 1B).

\section{FAF1 overexpression inhibits gastric cancer cell proliferation and induces apoptosis in vitro}

Using real-time PCR, we measured FAF1 mRNA levels in the HGC-27 and SGC7901 gastric cancer cell lines as well as in the GES-1 normal gastric epithelial
A
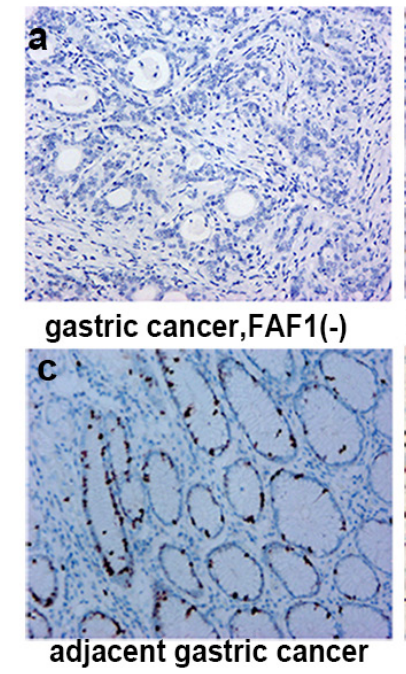

B

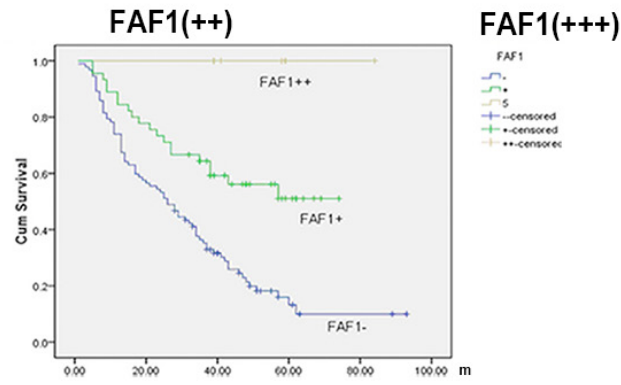

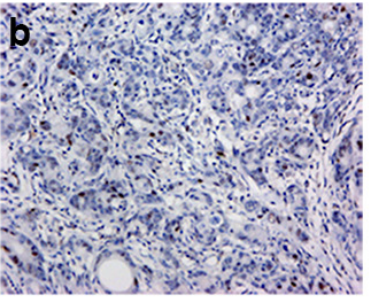
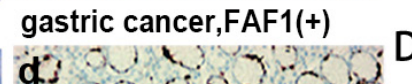

C

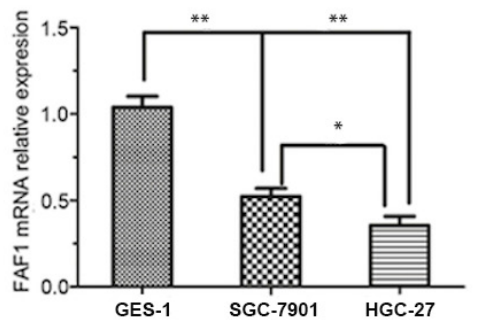

(

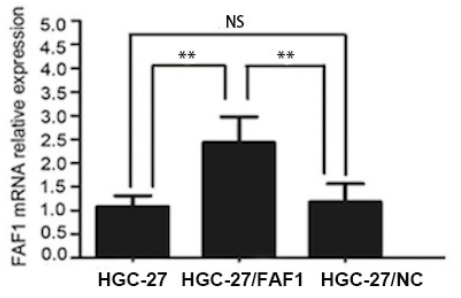

E

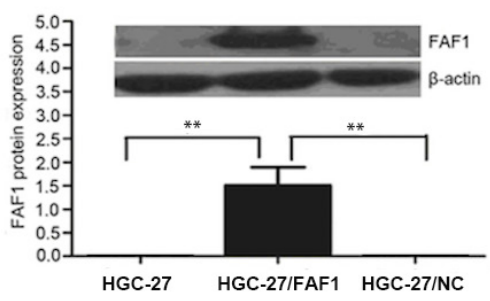

Figure 1: FAF1 is expressed at low levels in gastric cancer tissue, and it predicts poor prognosis. A. Expression of FAF1 protein in gastric cancer patients with immunohistochemistry, showing (a) negative expression in cancer tissue, (b) weakly positive expression in cancer tissue, (c) protein expression in adjacent tissue and (d) intense positive expression in normal tissue. Magnification, $\times 200$. B. Overall survival rate was significantly lower in patients with low or negative FAF1 expression after radical resection than in those with high FAF1 expression, based on the log-rank test. C. Relative levels of FAF1 mRNA measured by RT-PCR in GES-1, SGC-7901 and HGC-27 cell lines. Levels were significantly lower in HGC-27 and SGC-7901 cells than in GES-1 cells. D. Quantitative RT-PCR showed higher FAF1 mRNA levels in HGC-27/ FAF1 cells than in HGC-27/NC or HGC-27 cells. E. Western blotting showed higher FAF1 protein levels in HGC-27/FAF1 cells than in HGC$27 / \mathrm{NC}$ or HGC-27 cells. Data are mean $\pm \mathrm{SD}$ of three independent experiments $(\mathrm{n}=3)$. $* \mathrm{P}<0.05, * * \mathrm{P}<0.01$. NS, $\mathrm{P}>0.05$. 
Table 1: Correlation of FAF1 expression with clinicopathologic characteristics in patients with gastric cancer

\begin{tabular}{|c|c|c|c|c|}
\hline \multirow{2}{*}{ Parameter } & \multirow{2}{*}{$\mathbf{N}$} & \multicolumn{2}{|c|}{ FAF1-positive } & \multirow{2}{*}{$\mathbf{P}$} \\
\hline & & $\mathbf{n}$ & $\%$ & \\
\hline Gender & & & & 0.751 \\
\hline Male & 97 & 37 & 38.1 & \\
\hline Female & 48 & 17 & 35.4 & \\
\hline Age (years) & & & & 0.494 \\
\hline$\leqq 60$ & 86 & 34 & 37.3 & \\
\hline$>60$ & 59 & 20 & 37.0 & \\
\hline Tumor size (cm) & & & & 0.024 \\
\hline$<5$ & 80 & 36 & 45.0 & \\
\hline$\geqq 5$ & 65 & 18 & 27.6 & \\
\hline Tumor site & & & & 0.642 \\
\hline Cardia & 29 & 10 & 34.4 & \\
\hline Body & 22 & 8 & 36.3 & \\
\hline Antrum & 76 & 33 & 43.4 & \\
\hline Multiple sites & 18 & 3 & 16.6 & \\
\hline Histology grade of differentiation & & & & $<0.01$ \\
\hline Well-moderate & 28 & 21 & 75.0 & \\
\hline Poor-undifferentiated & 117 & 33 & 28.2 & \\
\hline Tumor infiltration & & & & $<0.01$ \\
\hline $\mathrm{T} 1$ & 9 & 7 & 77.7 & \\
\hline $\mathrm{T} 2$ & 25 & 16 & 64.0 & \\
\hline $\mathrm{T} 3$ & 67 & 22 & 32.8 & \\
\hline $\mathrm{T} 4$ & 44 & 9 & 20.4 & \\
\hline Lymph node metastasis & & & & $<0.01$ \\
\hline N0 & 59 & 32 & 54.2 & \\
\hline N1 & 86 & 22 & 25.5 & \\
\hline Distant metastasis & & & & 0.374 \\
\hline M0 & 130 & 50 & 38.4 & \\
\hline M1 & 15 & 4 & 26.6 & \\
\hline TNM stage & & & & $<0.01$ \\
\hline I & 27 & 20 & 74.0 & \\
\hline II & 56 & 22 & 39.2 & \\
\hline III & 47 & 8 & 17.0 & \\
\hline IV & 15 & 4 & 26.6 & \\
\hline
\end{tabular}

Table 2: Univariate Cox regression analysis to identify predictors of survival in patients with gastric cancer after radical surgery

\begin{tabular}{lccc}
\hline Factor & HR & $\mathbf{9 5 \%}$ CI & P \\
\hline Tumor diameter & 2.967 & $1.959-4.494$ & 0.000 \\
Anatomic site & 1.343 & $1.056-1.708$ & 0.016 \\
Tumor infiltration & 4.205 & $2.950-5.995$ & 0.000 \\
Histology grade & 3.470 & $1.735-6.940$ & 0.000 \\
Lymph node metastasis & 3.707 & $2.306-5.960$ & 0.000 \\
Distant metastasis & 8.891 & $4.753-16.632$ & 0.000 \\
TNM stage & 5.293 & $3.856-7.266$ & 0.000 \\
FAF1 expression & 0.330 & $0.209-0.522$ & 0.000 \\
\hline
\end{tabular}


cell line. Levels were much lower in the two cancer lines than in the normal line, and levels were lowest in HGC-27 cells (Figure 1C), so this line was chosen for subsequent experiments.

We engineered a recombinant lentivirus encoding FAF1, with which we infected HGC-27 cells. In parallel, we infected another set of cultures with a negative-control lentivirus encoding no transgene. Using real-time PCR, we found that cells infected with our recombinant lentivirus (HGC-27/FAF1) significantly overexpressed FAF1 relative to uninfected cells (HGC-27) or cells infected with negative-control virus (HGC-27/NC; $\mathrm{P}<0.01$, Figure 1D). Lentivirus infection on its own did not affect FAF1 expression levels, since levels were similar between HGC-27/NC and HGC-27 cells ( $\mathrm{P}=0.58$, Figure 1D). Consistent with these mRNA results, Western blotting
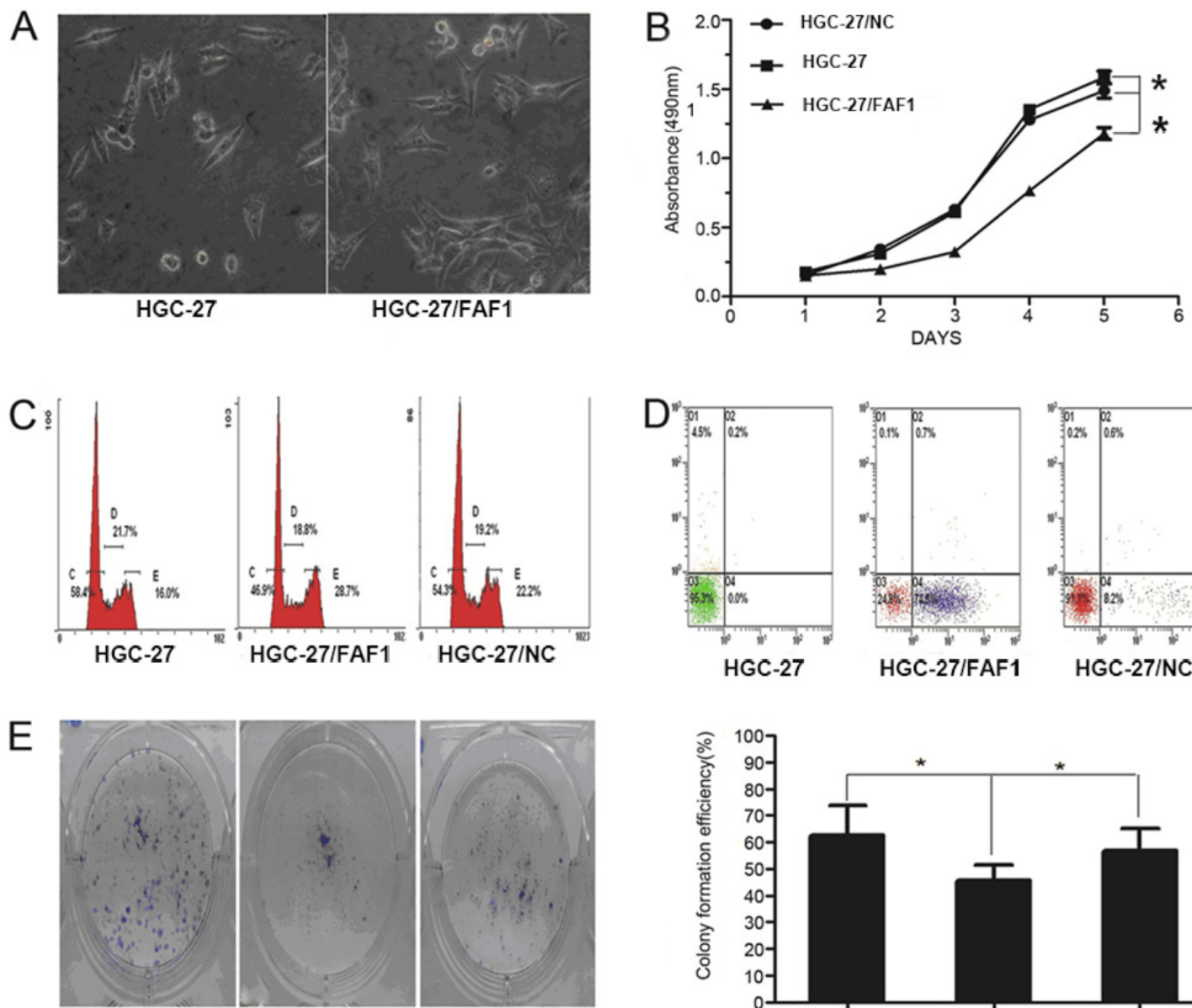

HGC-27
HGC-27
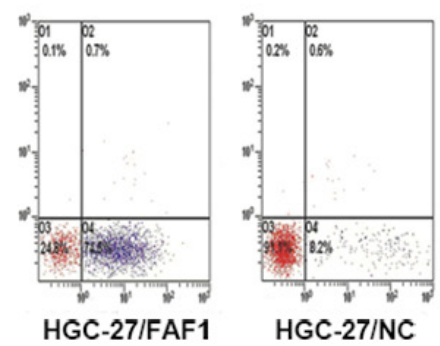

revealed significantly higher FAF1 protein levels in HGC$27 /$ FAF1 cells than in the other two groups $(\mathrm{P}<0.01$, Figure 1E).

We then examined the effects of FAF1 overexpression on key characteristics of gastric cancer cells. Overexpression significantly decreased proliferation $(\mathrm{P}<0.01$, Figure $2 \mathrm{~A}-2 \mathrm{~B})$, increased the proportion of cells in $\mathrm{G} 2 / \mathrm{M}$ stage $(\mathrm{P}<0.05$, Figure $2 \mathrm{C}$ ), increased the proportion of apoptotic cells $(\mathrm{P}<0.05$, Figure $2 \mathrm{D})$ and decreased colony formation $(\mathrm{P}<0.05$, Figure $2 \mathrm{E})$.

\section{FAF1 overexpression inhibits tumor growth}

To extend these in vitro experiments suggesting that FAF1 suppresses gastric cancer progression, we compared

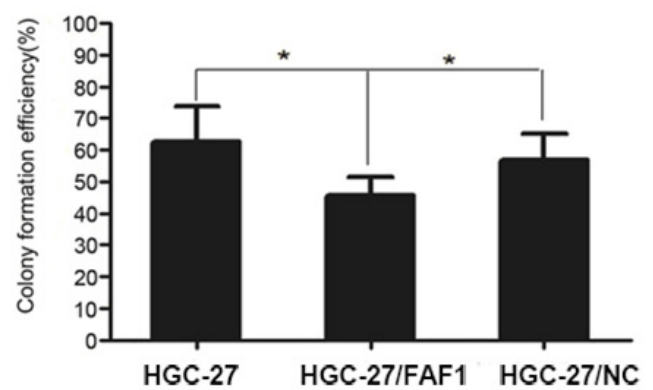

Figure 2: FAF1 overexpression inhibits gastric cancer cell proliferation and induces apoptosis in vitro. A. Morphological changes in HGC-27 cells as a result of FAF1 overexpression. B. Comparison of in vitro proliferation of HGC-27, HGC-27/FAF1 and HGC27/NC cells. C. Comparison of cell cycle distribution of HGC-27, HGC-27/FAF1 and HGC-27/NC cultures, based on flow cytometry. D. Comparison of apoptosis levels in HGC-27, HGC-27/FAF1 and HGC-27/NC cells, based on flow cytometry. E. Comparison of colony formation by HGC-27, HGC-27/FAF1 and HGC-27/NC cells. The left panel shows representative results for the three types of cells. Quantitation of colony numbers is shown in the right panel. Data are mean $\pm \mathrm{SD}$ of three independent experiments $(\mathrm{n}=3) . * \mathrm{P}<0.05, * * \mathrm{P}<0.01$. 
the growth of $\mathrm{HGC}-27 / \mathrm{FAF} 1, \mathrm{HGC}-27 / \mathrm{NC}$ or $\mathrm{HGC}$ 27 tumors in nude mice. Tumor volume at 28 days after injection was significantly smaller in mice injected with HGC-27/FAF1 cells than in mice injected with the other types of cells $(\mathrm{P}<0.05$, Figure $3 \mathrm{~A}-3 \mathrm{~B})$.

We next used Western blotting to compare levels of FAF1 protein among the three types of tumors. FAF1 expression was high in mice injected with HGC-27/FAF1 cells, but undetectable in mice injected with the other types of cells (Figure 3C). Immunohistochemistry of HGC-27/ FAF1 tumor sections showed FAF1 to localize in the cytoplasm (Figure 3D). Little or no immunohistochemical staining was observed for FAF1 in sections of HGC-27/ $\mathrm{NC}$ or HGC-27 tumors.

\section{Proteomics-based prediction of effects of FAF1 overexpression on $\boldsymbol{H}$. pylori-associated gastric carcinogenesis}

We established a proteomics database of HGC-27/ FAF1 cells infected with $H$. pylori, and "molecule activity predictor" analysis predicted that FAF1 up-regulation would inhibit the NF- $\kappa \mathrm{B}$ complex at the center of the network. This was corroborated by iTRAQ measurements

(Figure 4A). These results suggested that FAF1 overexpression should lead to a net increase in apoptosis of gastric cancer cells, which is consistent with the in vitro and in vivo experiments described above. Comparison of HGC-27/FAF1 infected or not infected with $H$. pylori showed that infection slightly reduced expression of FAF1 but increased expression of NF- $\kappa \mathrm{B}$, based on iTRAQ and Western blotting of total cell lysates (Figure 4B-4D).

\section{H. pylori may act via IKKßand p65 to down- regulate FAF1}

To identify how $H$. pylori infection may down-regulate FAF1 expression, we examined the effects of silencing IKK $\beta$ or p65 genes on FAF1 expression in the presence or absence of $H$. pylori infection. These two proteins are key downstream effectors of the NF- $\mathrm{NB}$ signaling pathway [12, 13]. HGC-27/FAF1 cells were transfected for $72 \mathrm{~h}$ with RNAi constructs targeting IKKßor p65, or with a non-coding negative-control RNAi construct. Then real-time PCR was used to compare levels of FAF1 mRNA in the different groups, while Western blotting was used to compare levels of FAF1 protein. When either IKK $\beta$ or p65 was knockeddown, $H$. pylori infection did not significantly down-regulate
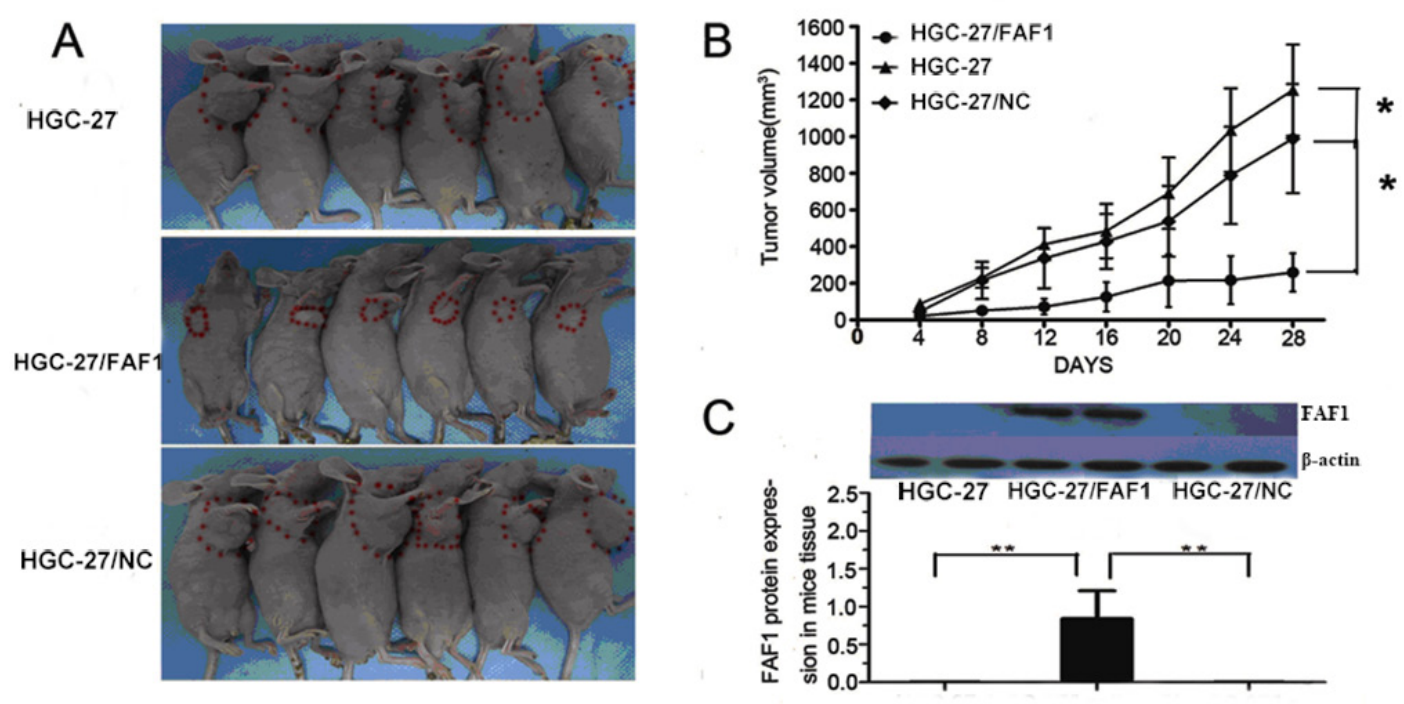

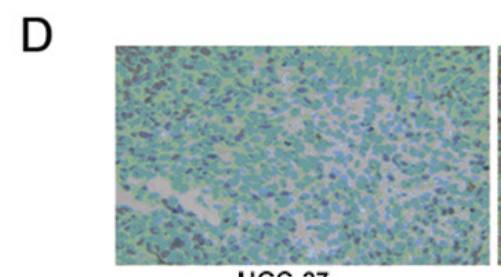

HGC-27

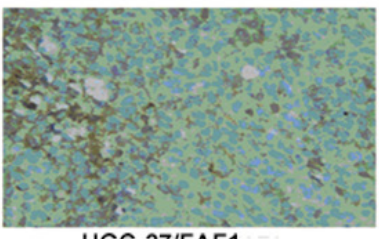

HGC-27/FAF1

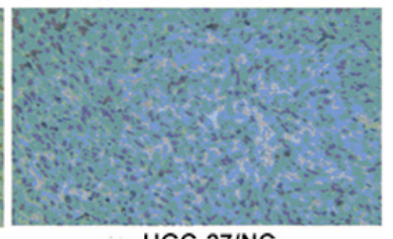

HGC-27/NC

Figure 3: FAF1 overexpression inhibits tumor growth in vivo. A. Tumor volume was significantly smaller in nude mice injected with HGC-27/FAF1 cells than in mice injected with HGC-27 or HGC-27/NC cells. B. Growth of HGC-27/FAF1 tumors in nude mice was significantly slower than growth of HGC-27 or HGC-27/NC tumors. C. FAF1 expression in tumor xenografts, based on Western blotting. D. FAF1 expression in tumor xenografts, based on immunohistochemistry. Six animals were analyzed for each treatment condition. $* \mathrm{P}<$ $0.05, * * \mathrm{P}<0.01$. 
FAF1 expression at the level of mRNA (Figure 5A) or protein (Figure 5B).

Western blotting further showed that knocking down IKK $\beta$ or p65 partially blocked $H$. pylori-induced I $\mathrm{B} \alpha$ degradation and IKKaup-regulation, and substantially blocked $H$. pylori-induced phosphorylation of IKK $\alpha / \beta$, p65 and $\mathrm{I} \kappa \mathrm{B} \alpha(\mathrm{P}<0.05$, Figure $5 \mathrm{C}-5 \mathrm{D})$. As a result, these knockdowns increased the level of unphosphorylated I $\kappa$ Barelative to the level of phosphorylated $\mathrm{I} \kappa \mathrm{B} \alpha(\mathrm{P}<0.05$, Figure $5 \mathrm{E})$. Knocking down either IKK $\beta$ or p65 also partially blocked H. pylori-induced secretion of the inflammatory cytokines TNF- $\alpha$ and IL-8 $(\mathrm{P}<0.05$, Figure 5F).

\section{DISCUSSION}

Here we investigated the potential involvement of FAF1 in gastric cancer and asked whether NF- $\mathrm{B}$ signaling pathways may mediate this involvement. Analysis of gastric cancer tissues suggests that FAF1 expression is quite low in these patients, and that low FAF1 expression may predict patient survival (Figure 1A-1B and Tables 1-2). Consistent with a protective role of FAF1 against gastric cancer, we found that FAF1 overexpression in gastric cancer cell lines reduced their proliferation and increased apoptosis (Figure 2A-2E). FAF1 overexpression also reduced tumor growth in vivo (Figure 3A-3D). Based on the predictions of proteomic reference pathways and networks in the presence of high FAF1 expression and $H$. pylori infection, we identified the NF- $\kappa$ B pathway as a potential mediator of the link between FAF1 and gastric cancer (Figure 4A-4D). Consistent with this idea, knocking down expression of the NF- $\kappa$ B activator proteins IKK $\beta$ or p65 blocked the ability of $H$. pylori to down-regulate FAF1 expression as well as trigger other proinflammatory changes linked to gastric cancer (Figure $5 \mathrm{~A}-5 \mathrm{~F})$. Taken together, our results suggest that FAF1 normally suppresses gastric carcinogenesis by promoting cell death and apoptosis, as well as by blocking the ability of H. pylori to stimulate NF- $\kappa$ B signaling.
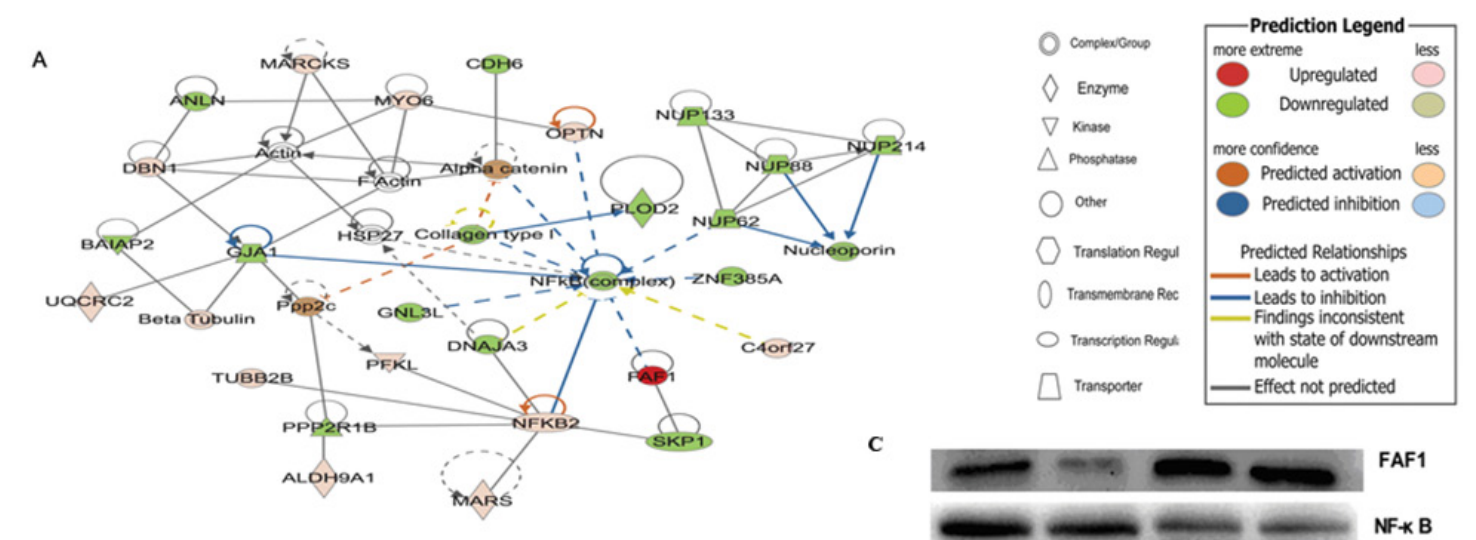

B
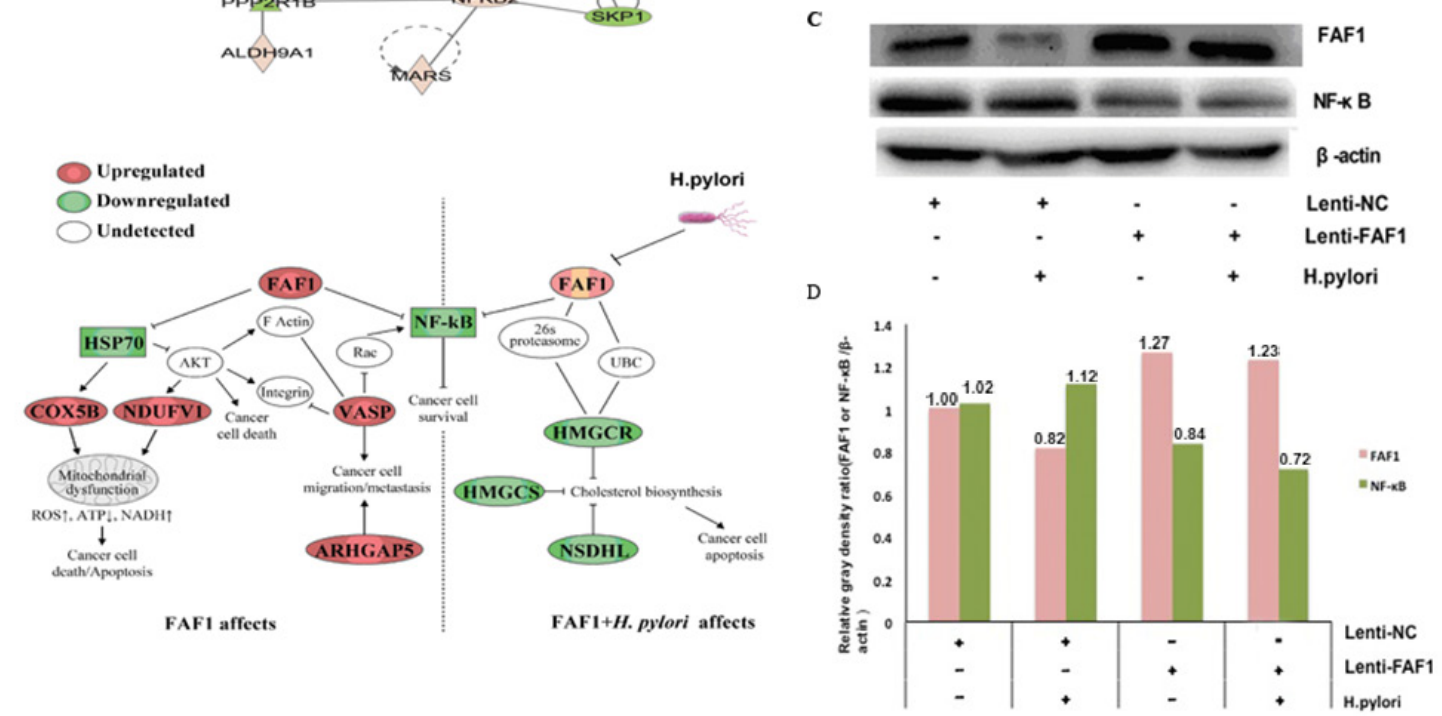

Figure 4: Map of pathways potentially involved in FAF1/H. pylori-associated gastric carcinogenesis based on iTRAQ quantification and Western blotting. A. Networks of protein inter-relationships were constructed using Ingenuity Pathway Analysis. Red proteins were predicted to be up-regulated, and green proteins to be down-regulated, in FAF1/H. pylori-associated gastric carcinogenesis. B. Protein interaction networks involving FAF1 and H. pylori. Analyzing these networks using the "molecule activity predictor" algorithm in Ingenuity Pathway Analysis generated predictions of the effects of FAF1 up- or down-regulation on downstream molecules. C. Western blotting validation of proteomics results based on different combinations of FAF1 overexpression, NF- $\kappa \mathrm{B}$ expression and/or $H$. pylori infection. D. Image J quantitation of relative FAF1 and NF- $\kappa B$ protein expression in different cell groups. Relative gray density ratios are shown above the bars. 
H. pylori virulence factors activate NF- $\kappa$ B [14] via canonical pathways involving activation of an IKK complex containing $\operatorname{IKK} \alpha$ and $\operatorname{IKK} \beta[15,16]$, phosphorylation and subsequent degradation of $\mathrm{I} \kappa \mathrm{B}$, and translocation of p65 to the nucleus, leading to DNA binding by NF- $\mathrm{B}$ [17-19]. Our results suggest that loss of FAF1 expression is related to greater NF$\kappa \mathrm{B}$ activation during gastric carcinogenesis, which is consistent with previous work [20]. Our finding that FAF1 is suppressed by $H$. pylori-activated NF- $\kappa \mathrm{B}$ signaling in gastric carcinogenesis, coupled with previous reports that FAF1 inhibits NF- $\kappa \mathrm{B}$ activity by interfering with nuclear translocation of p65 [21] and IKK $\beta$ [22], suggests a new set of interactions that can be analyzed more deeply to gain more insights into how gastric cancer progresses.

For example, we found here that knocking down key components of NF- $\kappa \mathrm{B}$ signaling down-regulated expression of TNF- $\alpha$ and IL-8. This leads us to propose that the up-

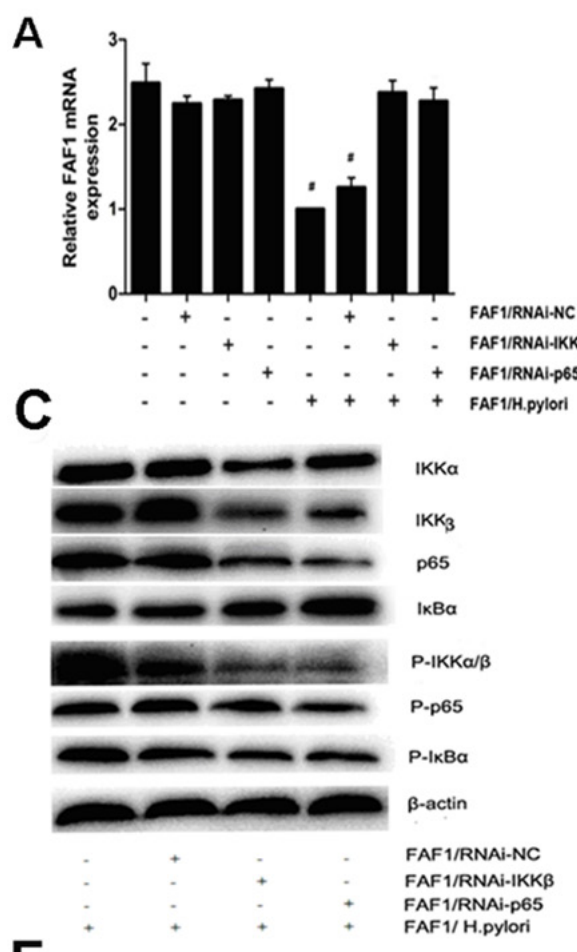

$\mathbf{E}$

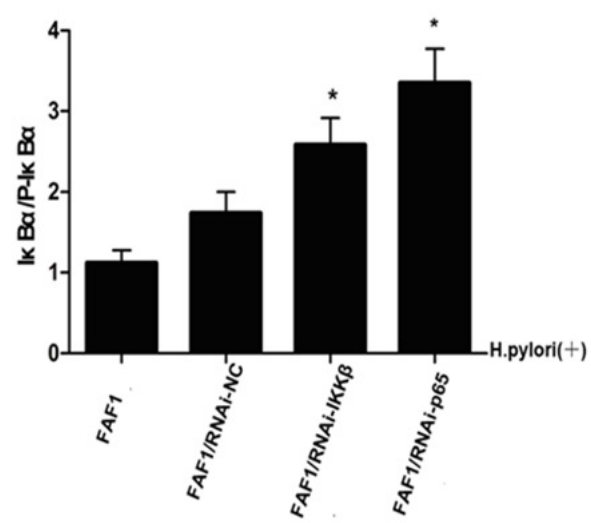

B
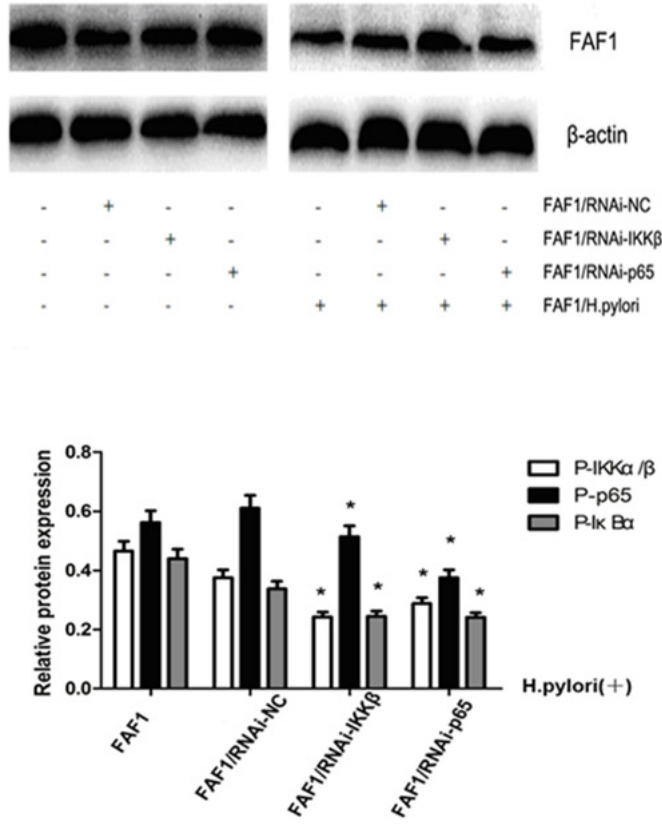

$\mathbf{F}$
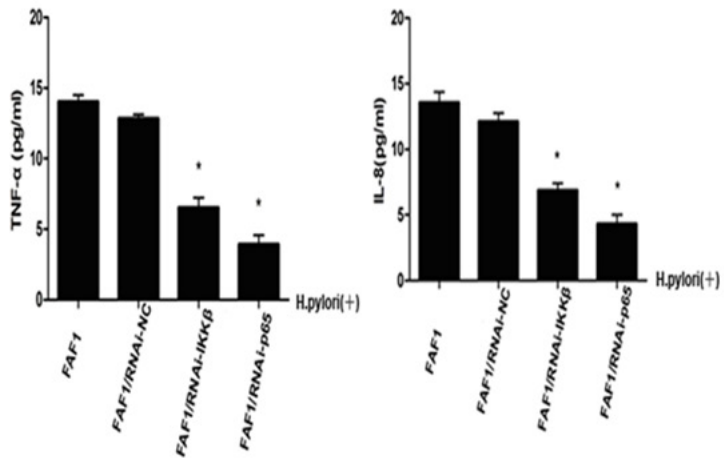

Figure 5: $\boldsymbol{H}$. pylori down-regulates FAF1 expression via the NF-кB signaling pathway. A. Quantitative RT-PCR analysis of FAF1 mRNA levels in HGC-27/FAF1 cells not transfected or transfected with negative-control RNAi (RNAi-NC) or with RNAi targeting IKKßor p65. Cells were infected or not with $H$. pylori. ${ }^{*} \mathrm{P}<0.05 v$ s untransfected cells or cells transfected with RNAi-NC. B. Western blotting of total lysates from HGC-27/FAF1 cells not transfected or transfected with negative-control RNAi (RNAi-NC) or with RNAi targeting IKK $\beta$ or p65. Cells were infected or not with $H$. pylori. C. Western blotting of proteins in the NF- $\mathrm{B}$ signaling pathway. D. Western blotting showed that levels of phosphorylated IKK $\alpha / \beta$, p65 and I $\mathrm{BB} \alpha$ were lower in RNAi targeting IKK $\beta$ or p65 than in untransfected

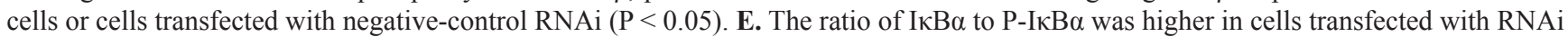
against IKK $\beta$ or $\mathrm{p} 65$ than in untransfected cells or cells transfected with negative-control RNAi $(* \mathrm{P}<0.05)$. F. Secretion of TNF- $\alpha$ and IL-8 was lower in $H$. pylori-infected cells transfected with RNAi against IKK $\beta$ or p65 than in $H$. pylori-infected cells that were untransfected or transfected with negative-control RNAi $(* \mathrm{P}<0.05)$. Data are the mean $\pm \mathrm{SD}$ of three independent experiments. 
regulation of TNF- $\alpha$ and IL-8 following $H$. pylori infection of gastric cells may contribute to FAF1 down-regulation.

It is also possible that FAF1 affects gastric cancer progression through mechanisms that do not depend on NF- $\kappa$ B. For example, Bessède et al showed that alterations in IQGAP1 signaling in the presence of $H$. pylori infection can promote the emergence of cancer stem cells and gastric adenocarcinoma development [23]. H. pyloriinduced inflammation leads to high gastric endothelial cell turnover and increased opportunities for DNA damage and somatic mutations $[24,25]$. It would be interesting to examine whether FAF1 is involved in any of these processes. FAF1 has been found to promote hydrogen peroxide-mediated necrotic cell death [26]. Whether this contributes to the observed tumor suppressive effects of FAF1 should be investigated.

In conclusion, we have provided evidence that FAF1 acts a tumor suppressor by regulating cell proliferation and apoptosis, and by inhibiting NF- $\mathrm{KB}$ signaling--such as after $\mathrm{H}$. pylori infection--that would otherwise stimulate secretion of pro-inflammatory cytokines and increase the risk of gastric carcinogenesis. Our work justifies studies into therapeutic approaches that target pathways that down-regulate FAF1, especially the NF-kB pathway as a result of $\mathrm{H}$. pylori infection.

\section{MATERIALS AND METHODS}

\section{Tissue samples}

A total of 145 gastric cancer samples were obtained from the same number of patients who underwent surgery at the Affiliated Tumor Hospital of Guangxi Medical University between April 2004 and December 2007. Patients were diagnosed with gastric cancer based on histopathology evaluation. None received local or systemic treatment before surgery. All gastric tissue samples were immediately frozen in liquid nitrogen, and stored at $-80^{\circ} \mathrm{C}$ until use. The study protocol was approved by the Research Ethics Committee of the Affiliated Tumor Hospital, and informed consent was obtained from all patients.

\section{Cell lines and animals}

Cell lines were obtained from the National Institute of Cells (Shanghai, China) and the Central Laboratory of Zhongnan University, Hunan, China. RPMI-1640 medium (Gibco, USA) was supplemented with $10 \%$ fetal bovine serum (Corning, USA), penicillin (100 U/mL) and streptomycin $(0.1 \mathrm{mg} / \mathrm{mL})$. Cells were cultured at $37^{\circ} \mathrm{C}$ in a humidified atmosphere of $5 \% \mathrm{CO}_{2}$.

Male nude mice aged 4-6 weeks were obtained from the animal center of Guangxi Medical University (Nanning, China) and fed a standard rodent diet under specific pathogen-free conditions. Animal care and all experimental procedures were approved by the Animal Ethics Committee of Guangxi Medical University.

\section{Preparation of $\boldsymbol{H}$. pylori culture filtrate}

Helicobacter pylori strain NCTC11637 was purchased from American Type Culture Collection (ATCC). H. pylori was taken from liquid nitrogen, inoculated onto Columbia blood agar plate medium containing $10 \%$ defibrinated sheep blood, and incubated at $37^{\circ} \mathrm{C}$ in a microaerobic environment $\left(5 \% \mathrm{O}_{2}, 10 \% \mathrm{CO}_{2}, 85 \% \mathrm{~N}_{2}\right)$. After $3 \mathrm{~d}$ of culturing, $H$. pylori was transferred to Brucella broth medium and incubated with shaking (130 rev/min) for $3 \mathrm{~d}$ at under $37^{\circ} \mathrm{C}$ under microaerobic conditions. $H$. pylori supernatant was prepared by centrifuging cultures at $12000 \mathrm{rev} / \mathrm{min}$ for $20 \mathrm{~min}$, concentrating and filtering the supernatant through a $0.22-\mu \mathrm{m}$ pore size, and storing at $-80^{\circ} \mathrm{C}$. Vacuolar cytotoxic activity was tested as described [27], with some modifications.

\section{Construction of lentivirus FAF1 overexpression vectors and RNAi vectors}

Lentivirus expression vectors encoding full-length human FAF1 (Lenti-FAF1) and empty control vector (Lenti-NC) were synthesized by Shanghai GeneChem (Shanghai, China). Constructs for RNA interference (RNAi) targeting the human NF- $\kappa \mathrm{B}$ p65 subunit mRNA (GenBank, NM_021975) or human NF-кB IKK $\beta$ subunit mRNA (GenBank, NM_001190720) were also synthesized by Shanghai GeneChem. As a negative RNAi control, a random non-coding RNA was synthesized (5'-TTC TCC GAA CGT GTC ACGT-3').

\section{Cell transfection}

HGC-27 cells were cultured in 6-well plates for $24 \mathrm{~h}$, then transfected with Lenti-FAF1 or Lenti-NC overexpression constructs using Lipofectamine ${ }^{\circledR} 2000$ Reagent (Invitrogen, Thermo Fisher Scientific) according to the manufacturer's instructions. Transfection efficiency was assessed at different time points using fluorescence microscopy. Puromycin ( $1 \mathrm{mg} / \mathrm{mL})$ was used to select stable transfectants. The resulting stably transfected cell lines were designated HGC-27/FAF1 and HGC-27/NC.

HGC-27/FAF1 cells were cultured in 6-well plates for $24 \mathrm{~h}$, then transfected with RNAi constructs targeting IKK $\beta$ or p 65 or with the negative-control construct using Lipofectamine ${ }^{\circledR} 2000$ according to the manufacturer's instructions. At different time points, transfection efficiency was assessed using fluorescence microscopy.

\section{Prediction of proteins involved in FAF1- regulated interaction networks}

To identify molecular details about how FAF1 and H. pylori may contribute to gastric carcinogenesis, we used iTRAQ labeling and LC-MS/MS to perform proteomic analysis of HGC-27/FAF1 and HGC-27/NC cells in the presence or absence of $H$. pylori infection. Protein samples 
were prepared for proteomic analysis as described [28], and iTRAQ 8-plex labeling and analysis were carried out following the manufacturer's instructions (Applied Biosystems, Foster City, CA, USA). The "molecule activity predictor" algorithm of Ingenuity pathway analysis (IPA) was used to predict whether a molecule of interest, pathway, network or function was up- or down-regulated under conditions of FAF1 overexpression and/or H. pylori infection. These predictions were then used to infer up- or down-regulation of upstream and downstream proteins.

\section{Protein extraction and western blotting}

Cells or mouse tissues were washed with pre-cooled phosphate-buffered saline (PBS) and lysed in RIPA lysis buffer containing $1 \mathrm{mmol} / \mathrm{L}$ phenylmethylsulfonyl fluoride (PMSF) for $30 \mathrm{~min}$ on ice. Clarified protein extracts were obtained by centrifugation for $30 \mathrm{~min}$ at $4^{\circ} \mathrm{C}$ at 12000 $\mathrm{rev} / \mathrm{min}$. Protein concentration was determined using a BCA protein assay kit (Boster, Wuhan, China). Lysate $(100 \mu \mathrm{g})$ was mixed with loading buffer containing $5 \%$ $\beta$-mercaptoethanol, and heated for $5 \mathrm{~min}$ at $100^{\circ} \mathrm{C}$. Samples were separated by sodium dodecyl sulfate-polyacrylamide gel electrophoresis (SDS-PAGE), and proteins were transferred onto PVDF membrane filters (Millipore, USA) by wet blotting. Membranes were incubated for $1 \mathrm{~h}$ at room temperature in blocking buffer $(1 \times$ TBS with $0.1 \%$ Tween-20 and 5\% skim milk), then incubated overnight at $4^{\circ} \mathrm{C}$ with a primary antibody against FAF1 (1:1500; GeneTex, USA) or a primary antibody against one of the following (Cell Signaling Technology, USA): NF-кB (1:1000), p65 (1:1000), IKK $\alpha / \beta$ (1:1000), IкB $\alpha(1: 1000)$, P-p65 (1:1000), P-IKK $\alpha / \beta(1: 1000), \quad$ P-IкB $\alpha(1: 1000)$ and $\beta$-actin (1:1000). Membranes were incubated with the corresponding horseradish peroxidase-conjugated secondary antibody (1:2000; Cell Signaling Technology) for $1 \mathrm{~h}$ at room temperature. Finally, membranes were analyzed using an ECL system (Beyotime, Shanghai, China) and quantitated using Bio-Rad Quantity One software 4.62.

\section{Total RNA extraction and quantitative real-time PCR}

Total RNA was extracted from cells or mouse tissue using Trizol (Invitrogen, CA, USA) according to the manufacturer's instructions, and RNA concentration was measured using the Nano Drop 2000 (Thermo Fisher Scientific). RNA template $(3 \mu \mathrm{g})$ was reverse-transcribed using the first-strand cDNA synthesis kit (Thermo Fisher Scientific). Quantitative real-time PCR was performed in two steps using the MxPro 3000 system and SYBR Premix Ex Taq PCR (Takara, Dalian, China). PCR conditions were as follows: $95^{\circ} \mathrm{C}$ for $30 \mathrm{sec}$, followed by 40 cycles of $95^{\circ} \mathrm{C}$ for $5 \mathrm{sec}$ and $60^{\circ} \mathrm{C}$ for $34 \mathrm{sec}$. PCR primers were as follows: FAF1, 5'-CTTGCTGAATCAGGGCTCTC-3' (forward), 5'-TCCACCCCAAATTCTGTAGC-3' (reverse);
IKK $\beta$, 5'-GGCAAACCGTACTCCAAGCAC-3' (forward), 5'-CCTTGTCTGCACACTGGAGGTC-3' (reverse); p65, 5'-GGGAAGGAACGCTGTCAGAG-3' (forward), 5'-TAG CCTCAGGGTACTCCATCA-3' (reverse); $\beta$-actin, $5^{\prime}$-AC CGAGCGCGGCTACAGC-3' (forward), 5'-CTC ATTGCCAATGGTGAT-3' (reverse). Levels of mRNA were calculated based on threshold cycle $(\mathrm{Ct})$ values and normalized to levels of $\beta$-actin mRNA. Results were analyzed using the $2^{-\Delta \Delta \mathrm{Ct}}$ method and the formula $\Delta \Delta \mathrm{Ct}=$ Sample (Avg - FAF1/IKK $\beta /$ p65 Ct - Avg • $\beta$-actin Ct) Control (Avg • FAF1/IKK $\beta /$ p65 Ct - Avg $\bullet \beta$-actin Ct).

\section{Cell proliferation assay}

Cells $\left(0.5 \times 10^{4}\right.$ per well $)$ were seeded into 96 well plates in a final volume of $100 \mu \mathrm{l}$. Every $24 \mathrm{~h}, 10$ $\mu \mathrm{l}$ of Cell Counting Kit-8 solution (CCK-8, Dojindo) was added to each well of one plate, and the plate was further incubated for $2 \mathrm{~h}$ at $37^{\circ} \mathrm{C}$. Absorbance at $450 \mathrm{~nm}$ was measured using a microplate reader (MK3, Thermo Electron Corporation, MA, USA). The experiment was performed over five consecutive days.

\section{Cell cycle analysis}

Cells $\left(1 \times 10^{6}\right.$ per well $)$ were seeded into 6-well culture plates, and transfected with Lenti-FAF1 or LentiNC. Cells were allowed to grow to $90 \%$ confluence, then treated with trypsin, centrifuged, washed twice with icecold PBS, and fixed in $70 \%$ cold ethanol at $4{ }^{\circ} \mathrm{C}$ overnight. Cells were incubated in $100 \mu \mathrm{l}$ RNase A (eBioscience, $\mathrm{CA}, \mathrm{USA}$ ) at $37^{\circ} \mathrm{C}$ for $30 \mathrm{~min}$, then in $400 \mu \mathrm{l}$ propidium iodide (eBioscience) at $4^{\circ} \mathrm{C}$ for $30 \mathrm{~min}$. Stained cells were analyzed by flow cytometry (EpicsXL, Beckman, CA, USA) using EXPO32 ADC analysis software.

\section{Cell apoptosis analysis}

Cells $\left(1 \times 10^{6}\right.$ per well $)$ were seeded into 6-well culture plates and transfected with Lenti-FAF1 or Lenti$\mathrm{NC}$ as described above. Cells were allowed to grow to $90 \%$ confluence, washed once with PBS, washed once with $1 \times$ binding buffer (eBioscience), collected, and resuspended in $1 \times$ binding buffer. Fluorochromeconjugated Annexin V PE ( $5 \mu \mathrm{l}$; eBioscience) was added to $100 \mu \mathrm{l}$ of cell suspension, and the mixture was incubated for $15 \mathrm{~min}$ at room temperature away from light. Then cells were washed with $1 \times$ binding buffer, centrifuged, resuspended in $200 \mu \mathrm{l} 1 \times$ binding buffer and mixed with $5 \mu \mathrm{l}$ 7-AAD Viability Staining Solution (eBioscience). Finally the suspension was analyzed using flow cytometry as described above.

\section{Colony formation assay}

HGC-27/FAF1 or HGC-27/NC cell lines were cultured for $14 \mathrm{~d}$, then stained with gentian violet. The 
number of colonies containing more than 50 cells was determined. Results were the average of three independent experiments.

\section{Construction of mouse xenograft model}

HGC-27/FAF1 or HGC-27/NC cells $\left(1 \times 10^{7}\right)$ in $0.2 \mathrm{ml}$ of PBS were injected subcutaneously into the right armpit of male nude mice. Tumor diameter was measured every 3-4 d for 4 weeks. Tumor volume $\left(\mathrm{mm}^{3}\right)$ was estimated by measuring the longest and shortest diameter of the tumor and applying the formula: volume $=$ (shortest diameter $)^{2} \times($ longest diameter $) \times 0.5$.

\section{Histology}

Immunohistochemistry was used to detect FAF1 protein expression. Samples of gastric cancer tissue, adjacent tissue and normal gastric tissue were fixed in $10 \%$ neutral-buffered formalin at room temperature for $48 \mathrm{~h}$ and embedded in paraffin. Tissue sections were incubated with goat polyclonal antibody against FAF1 (1:100; Santa Cruz, CA, USA), followed by peroxidaseconjugated rabbit anti-goat secondary antibody (1:500; Cell Signaling Technology). Signal was detected using colorimetry based on 3,3-diaminobenzidine (DAB). Xenograft sections from mice injected with HGC-27/ FAF1 or HGC-27/NC cells were analyzed in the same way.

\section{ELISA of proinflammatory cytokines}

Cells $\left(1 \times 10^{5}\right.$ per well $)$ were cultured in 6-well plates, and transfected with RNAi constructs targeting IKK $\beta$ or $\mathrm{p} 65$ or with the negative-control RNAi construct. Transfected cells were then infected with $H$. pylori for 24 $h$ at a multiplicity of infection of 100:1. Levels of TNF- $\alpha$ and IL-8 secreted by infected cells were determined using a commercial ELISA (KeyGen BioTech, Nanjing, China) according to the manufacturer's instructions. Absorbance at $450 \mathrm{~nm}$ was measured using an ELISA plate reader.

\section{Statistical analysis}

All data were expressed as mean \pm standard deviation (SD) and analyzed using SPSS 16.0 (IBM, Chicago, IL, USA). Inter-group differences in the rate of FAF1 positivity were assessed for significance using the chi-squared test; inter-group differences in survival curves, using the log-rank test; and inter-group differences in mRNA or protein levels, using one-way ANOVA or the Kruskal-Wallis H test, followed by the SNK post hoc test. Differences in tumor growth and volume were assessed for significance using multivariate analysis. Experiments were performed three times independently. Statistical significance was defined as $\mathrm{P}$ $<0.05$.

\section{ACKNOWLEDGMENTS}

The authors thank Dr Armando Chapin Rodríguez for his language editing and helpful comments, which substantially improved the quality of the manuscript.

\section{CONFLICTS OF INTEREST}

No potential conflicts of interest were disclosed.

\section{FUNDING}

This study was supported by the Natural Science Foundation of Guangxi (grant 2012GXNSFDA053021), a Postdoctoral Science Foundation funded project of Guangxi Medical University (grant 02306214010D), and the Important Projects Fund of Guangxi Health Department (grant 2012092).

\section{Author contributions}

A-Q L and L-Y G designed the study. A-Q L and Z-Q X processed clinical samples. X-N C and J F performed cell and animal experiments. J-W C and F-J Q performed the interaction networks analysis. A-Q L wrote the manuscript, to which all other authors contributed. All authors approved the final version of the manuscript.

\section{REFERENCES}

1. Liang L, Fang JY, Xu J. Gastric cancer and gene copy number variation: emerging cancer drivers for targeted therapy. Oncogene 2016; 35:1475-1482.

2. Miller KD, Siegel RL, Lin CC, Mariotto AB, Kramer JL, Rowland JH, Stein KD, et al. Cancer treatment and survivorship statistics, 2016. CA Cancer J Clin 2016; 66:271-289.

3. Menges CW, Altomare DA, Testa JR. FAS-associated factor 1 (FAF1): diverse functions and implications for oncogenesis. Cell Cycle 2009; 8:2528-2534.

4. Hidalgo A, Baudis M, Petersen I, Arreola H, Pina P, Vazquez-Ortiz G, Hernandez D, et al. Microarray comparative genomic hybridization detection of chromosomal imbalances in uterine cervix carcinoma. Bmc Cancer 2005; 5.

5. Bea S, Salaverria I, Armengol L, Pinyol M, Fernandez V, Hartmann EM, Jares P, et al. Uniparental disomies, homozygous deletions, amplifications, and target genes in mantle cell lymphoma revealed by integrative high-resolution whole-genome profiling. Blood 2009; 113:3059-3069.

6. Altomare DA, Menges CW, Pei J, Zhang L, Skele-Stump KL, Carbone M, Kane AB, et al. Activated TNF-alpha/ NF-kappaB signaling via down-regulation of Fasassociated factor 1 in asbestos-induced mesotheliomas 
from Arf knockout mice. Proc Natl Acad Sci U S A 2009; 106:3420-3425.

7. Liu AQ, Ge LY, Ye XQ, Luo XL, Luo Y. Reduced FAF1 Expression and Helicobacter Infection: Correlations with Clinicopathological Features in Gastric Cancer. Gastroenterol Res Pract 2012; 2012:153219.

8. Megraud F, Bessede E, Varon C. Helicobacter pylori infection and gastric carcinoma. Clin Microbiol Infect 2015.

9. Sheh A, Lee CW, Masumura K, Rickman BH, Nohmi T, Wogan GN, Fox JG, et al. Mutagenic potency of Helicobacter pylori in the gastric mucosa of mice is determined by sex and duration of infection. Proc Natl Acad Sci U S A 2010; 107:15217-15222.

10. Shimoyama A, Saeki A, Tanimura N, Tsutsui H, Miyake K, Suda Y, Fujimoto Y, et al. Chemical synthesis of Helicobacter pylori lipopolysaccharide partial structures and their selective proinflammatory responses. Chemistry 2011; 17:14464-14474.

11. Shigematsu Y, Niwa T, Rehnberg E, Toyoda T, Yoshida S, Mori A, Wakabayashi M, et al. Interleukin-1beta induced by Helicobacter pylori infection enhances mouse gastric carcinogenesis. Cancer Lett 2013; 340:141-147.

12. Valovka T, Hottiger MO. p65 controls NF-kappaB activity by regulating cellular localization of IkappaBbeta. Biochem J 2011; 434:253-263.

13. Ma XF, Zhang J, Shuai HL, Guan BZ, Luo X, Yan RL. IKKbeta/NF-kappaB mediated the low doses of bisphenol A induced migration of cervical cancer cells. Arch Biochem Biophys 2015; 573:52-58.

14. Nagashima H, Iwatani S, Cruz M, Jimenez Abreu JA, Uchida T, Mahachai V, Vilaichone RK, et al. Toll-like Receptor 10 in Helicobacter pylori Infection. J Infect Dis 2015.

15. Kim ML, Jeong HG, Kasper CA, Arrieumerlou C. IKKalpha contributes to canonical NF-kappaB activation downstream of Nod1-mediated peptidoglycan recognition. PLoS One 2010; 5:e15371.

16. Qu L, Ji Y, Zhu X, Zheng X. hCINAP negatively regulates NF-kappaB signaling by recruiting the phosphatase PP1 to deactivate IKK complex. J Mol Cell Biol 2015.

17. Schmerwitz UK, Sass G, Khandoga AG, Joore J, Mayer BA, Berberich N, Totzke F, et al. Flavopiridol protects against inflammation by attenuating leukocyte-endothelial interaction via inhibition of cyclin-dependent kinase 9. Arterioscler Thromb Vasc Biol 2011; 31:280-288.

18. Brechmann M, Mock T, Nickles D, Kiessling M, Weit N, Breuer R, Muller W, et al. A PP4 holoenzyme balances physiological and oncogenic nuclear factor-kappa B signaling in T lymphocytes. Immunity 2012; 37:697-708.

19. Hayden MS, Ghosh S. Regulation of NF-kappaB by TNF family cytokines. Semin Immunol 2014; 26:253-266.

20. Song J, Park JK, Lee JJ, Choi YS, Ryu KS, Kim JH, Kim E, et al. Structure and interaction of ubiquitin-associated domain of human Fas-associated factor 1. Protein Sci 2009; 18:2265-2276.

21. Hyland PL, Lin SW, Hu N, Zhang H, Wang L, Su H, Wang $\mathrm{C}$, et al. Genetic variants in fas signaling pathway genes and risk of gastric cancer. Int J Cancer 2014; 134:822-831.

22. Sul JW, Park MY, Shin J, Kim YR, Yoo SE, Kong YY, Kwon $\mathrm{KS}$, et al. Accumulation of the parkin substrate, FAF1, plays a key role in the dopaminergic neurodegeneration. Hum Mol Genet 2013; 22:1558-1573.

23. Bessède E, Molina S, Amador LA, Dubus P, Staedel C, Chambonnier L, Buissonnière A, Sifré E, Giese A, Bénéjat L, Rousseau B, Costet P, Sacks DB, et al. Deletion of IQGAP1 promotes Helicobacter pylori-induced gastric dysplasia in mice and acquisition of cancer stem cell properties in vitro. Oncotarget. 2016; 7:80688-80699. doi: 10.18632/oncotarget.12486.

24. Hanada K, Graham DY. Helicobacter pylori and the molecular pathogenesis of intestinal-type gastric carcinoma. Expert Rev Anticancer Ther 2014; 14:947-954.

25. Hanada K, Uchida T, Tsukamoto Y, Watada M, Yamaguchi $\mathrm{N}$, Yamamoto K, Shiota S, et al. Helicobacter pylori infection introduces DNA double-strand breaks in host cells. Infect Immun 2014; 82:4182-4189.

26. Yu C, Kim BS, Kim E. FAF1 mediates regulated necrosis through PARP1 activation upon oxidative stress leading to dopaminergic neurodegeneration. Cell Death Differ 2016.

27. Pessina A, Bayo M, Croera C, Meringolo F, Neri MG, Montesissa L, Raimondi A. In vitro sensitivity of human gastric cancer cells (HGC-27) to Helicobacter pylori cytotoxin. Scand J Gastroenterol 2003; 38:1228-1234.

28. Fuccio L, Zagari RM, Eusebi LH, Laterza L, Cennamo V, Ceroni L, Grilli D, et al. Meta-analysis: can Helicobacter pylori eradication treatment reduce the risk for gastric cancer? Ann Intern Med 2009; 151:121-128. 